\title{
Calculation of Aqueous Solubility of Organic Compounds
}

\author{
Yadu B. Tewari, Michele M. Miller, and Stanley P. Wasik \\ National Bureau of Standards, Washington, DC 20234
}

August 26, 1981

\begin{abstract}
The aqueous solubility of 14 organic solutes has been calculated from their octanol/water partilion eoefficient and from their solute activity coefficicnt in octanol at infinite dilution. The solute activity coefficients were calculated from the Flory-Huggins and Hildebrand-Scatchard (FH-HS) equations and were found to be in good agreement with the activity coefficients deternined from GC speeific retention volume measurements. The calculatcd solubilities were in good agreement with the experimental solubilitics.
\end{abstract}

Key words: activity coefficients, gas chromatography, octanol/water partition eoefficients, solubility parameters.

\section{Introduction}

The octanol/water partition coefficient, $K_{o / w}$, and the aqueous solubility, $C^{s}$, of organie compounds have been used widely to assess and prediet the fate of toxic substances in the marine environment. Both of these quantities have been successfully correlated with environmental partitioning phenomenon such as bioconcentration and sorption. These two quantities are thermodynamically related via eq (1) [1]. ${ }^{1}$

$$
K_{o / w}=\frac{\gamma_{\phi}^{\omega}}{\gamma_{\phi}^{o}}
$$

where $\gamma_{\phi}^{\omega}$ and $\gamma_{\phi}^{o}$ are the activity coefficients at infinite dilution based on volume fraction for the solute in water and in $n$-octanol, respectively. The quantity, $\gamma_{\phi}^{\omega}$, is generally defined as the reciprocal of the volume fraction of the solute in water, i.e. $\frac{1}{\phi}$, and is expressed as the reciprocal of the solute concentration in water $\left(C^{s}\right)$ times the molar volume of the solute $(V), 1 / C^{s} V$.

Hansch, Quinlan, and Lawrence [2] have developed a method for estimating $K_{o / w}$ based on the additivity principle of thermodynamic properties. On this basis group contributions to $\log K_{o / w}$ or $\Pi$ values are defined by eq (2).

$$
\Pi_{x}=\log K_{o / w}(x)-\log K_{o / w}(h)
$$

where $K_{o / w}(x)$ is the partition coefficient of a derivative and $K_{o / w}(h)$ is that of the parent molecule. Despite evidenee that

\footnotetext{
- Center for Chemical Physics, National Measurcinent Laboratory.

'Figures in brackets indicale literature references al the eud of this paper.
}

$\Pi$ values are often not additive, usually for steric reasons but sometimes through electronic and hydrogen bonding effects, there are many series of compounds in which $\Pi$ appears to be invariant.

Equations (1) and (2) suggest that the aqueous solubility, $C^{s}$, may be calculated from the molecular structure of the solute provided $\gamma_{\phi}^{o}$ can be estimated with some degree of accuracy. There are methods [3] availablc for calculating $\gamma_{\phi}^{o}$ from the solute physical properties. Because of the simplicity of the calculations, the Flory-Huggins and HildebrandScatchard (FH-HS) method was chosen to evaluate $\gamma_{\phi}^{o}$.

According to solution theories [4], the solute activity coefficient $\left(\gamma_{x}\right)$ based on mole fraction consists of an athermal term and a thermal term. At infinite dilution, in terms of the Flory-Huggins equation for the athermal term and the Hildebrand-Scatchard equation for the thermal term, this may be expressed [5] as

$$
\ln \gamma_{x}^{\infty}=\ln \frac{1}{r}+\left(1-\frac{1}{r}\right)+\frac{V}{R T}\left(\delta^{\prime}-\delta\right)^{2}
$$

where $r$ is the ratio of the molar volume of the solveut $V^{\prime}$ to that of the solute $V,\left(\frac{V^{\prime}}{V}\right)$, and the $\delta$ and $\delta^{\prime}$ are, respectively, the solute and solvent solubility parameters. These are defined [6] as

$$
\delta=\left(\frac{\Delta E_{v}}{V}\right)^{1 / 2}=\left(\frac{\Delta H_{v}-R T}{V}\right)^{1 / 2}
$$

where $\Delta E_{v}$ and $\Delta H_{v}$ are, respectively, the molar energy and enthalpy of vaporization. At infinite dilution the volume fraction activity coefficient $\left(\gamma_{\phi}^{\infty}\right)$ may be expresscd in terms of 
mole fraction activity coefficient $\left(\gamma_{x}^{\infty}\right)$ by the following equation $[5,7]$.

$$
\gamma_{\phi}^{\infty}=\gamma_{x}^{\infty}\left(\frac{V^{\prime}}{V}\right)
$$

Now combining eq (3) and (5), the solute activity coefficient $\gamma_{\phi}^{\infty}$ may be expressed as

$$
\ln \gamma_{\phi}^{\infty}=\left(1-\frac{1}{r}\right)+\frac{V}{R T}\left(\delta^{\prime}-\delta\right)^{2}
$$

In this paper we are concerned with estimating the solute activity coefficients in water, $\gamma_{\phi}^{2,}$, using eq 1 , from the estimated values of $\gamma_{\phi}^{o}$ and the experimental values of $K_{o / w^{*}}$. Activity coefficients, $\gamma_{\phi}^{\infty}$, in octanol for a number of solutes have also been calculated from the Flory-Huggins and Hildebrand-Scatchard equations and compared with the expcrimental values obtained by the gas chromatographic (GC) method.

\section{Experimental Procedure}

The stationary phase, $n$-octanol, used in this study was obtained from the Aldrich Chemical Company. The purity was checked by GC and was found to be $99+$ mole $\%$. The stationary phase was coated onto the support material, Chromosorb W-HP, 100/120 mesh, and the weight percent of coating was determined by an ashing method [8]. A stainless steel column ( $1 / 8$ in OD) was then packed with a known amount of the coated support and was connected to a HewlettPackard $5830 \mathrm{~A}^{2}$ gas chromatograph equipped with a flame ionization detector (FID) for the determination of the solute retention time. The temperature of the column was controlled by circulating water through a copper tubing jacket around the column and by a Haake Model FK temperature regulator which rcgulated the water temperature to $25.0 \pm 0.05^{\circ} \mathrm{C}$.

The column inlet pressure, measured with a precalibrated pressure gauge (range 0-15 PSI), was kept constant during a run by regulating with a precision valve. In order to measure the carrier gas flow rate the column was disconnected from the FID, just before and after the experiment, and a soap bubble flowmeter was connected to the column outlet. The carrier gas was presaturated with $n$-octanol in order to reduce bleeding of the stationary phase.

Since the retention times decreased as the experiment progressed due to column loss of the $n$-octanol, toluene was used as a reference retention time standard and injected with each

\footnotetext{
2 Cerlain trade names and company products are identified in order to adequalely specify the experimental procedure. In no case docs such identification imply recommendation or endorsement by the Nutionul Bnreau of Stundurds, nor does il imply thet the products are necessarily the best availahle for the purpose.
}

solute. The measured retention times were then corrected for bleeding using the reference solutc retention time.

The solute spccific retention volumes $\left(V_{g}^{o}\right)$ were calculated by using the following equation [9].

$$
V_{s}^{0}=\frac{t_{R} \cdot F}{w} \cdot \frac{P_{a}-P_{w}}{P_{a}} \cdot \frac{273.2}{T_{a}} \cdot \frac{3}{2} \cdot \frac{\left(P_{l} / P_{a}\right)^{2}-1}{\left(P_{i} / P_{a}\right)^{3}-1}
$$

where $t_{R}$ is the retention time (min), $F$ is the carrier gas flow rate ( $\mathrm{ml} / \mathrm{min}), P_{i}$ and $P_{a}$ are the column inlet and atmospheric pressure (in Torr), $P_{1 v}$ is the saturated water vapor pressure (in Torr) at room temperature $T_{a}\left({ }^{\circ} \mathrm{K}\right.$ ), and $W$ is the wcight (in gram) of stationary phase packed in the column. The reported specific retention volumes listed in column 1 of table 1 are an average of 6 measurements.

\section{Results and discussion}

The solute activity coefficients at infinite dilution $\left(\gamma_{\chi}^{\infty}\right)$ werc determined from the following equation [8].

$$
\ln \gamma_{X}^{\infty}=\ln \frac{273.2 R}{P^{\circ} V_{B}^{o} M^{\prime}}-\frac{P^{\circ} B}{R T}
$$

where $M^{\prime}$ is the molecular weight of stationary phase, $n$ octanol, ( $\mathrm{g} / \mathrm{mole}$ ), $P^{\circ}$ and $B$ are, respectively, the vapor pressure (in Torr) and the gas phase second virial coefficient $(\mathrm{ml} /$ mole) of the pure solute at temperature $T\left({ }^{\circ} \mathrm{K}\right)$, and $R$ is the gas constant. The second virial coefficients were calculated from the McGlashan and Potter equation [10] using the constants tabulated by Dreisbach $[11,12,13]$ and Timmermans [14]. These sources were also used for Antoine constants to calculate values of $P^{\circ}$ and for constants for the law of rectilinear diamcters to compute values of molar volumes. The solute mole fraction and volume fraction activity coefficients listed in table 1 wcre calculated using equations 8 and 5 . It is estimatcd that the probable uncertainty in the activity coefficients listed in table 1 is about $2 \%$.

The solute solubility parameters, $\delta$, listed in table 1 were calculated from their molar enthalpies of vaporization listed in the Dreisbach compilations $[11,12,13]$; whereas the solvent solubility parameter, $\delta^{\prime}$ was treated as an adjustablc parameter. In order to fit the experimental data of the systems studied, two different solubility parameters $\left(\delta^{\prime}\right)$ were used, one for aromatic solutes $\left(\delta^{\prime}=6.71\right)$ and another for aliphatic solutes $\left(\delta^{\prime}=9.57\right)$. The solute activity coefficients calculated using equation 6 are listed in column 5 of table 1 . The agreement between the two sets of data (calculated and experimental activity coefficients) is in general good. The avcrage deviation is $8.7 \%$; however, in a few systems it is as high as $18 \%$. These results suggest that the activity coefficient of a system may be calculated from the knowledge of their 
TABLE 1. Specific Retention Volumes $\left(V_{g}^{\circ}\right)$ and Solute Activity Coefficients in n-Octanol at $25.0^{\circ} \mathrm{C}$.

\begin{tabular}{|c|c|c|c|c|c|c|}
\hline Solute & $\begin{array}{c}\mathrm{V}_{\mathrm{g}}^{3} \\
(\mathrm{ml} / \mathrm{g})\end{array}$ & $\gamma_{x}^{x}$ & $\begin{array}{c}\gamma_{\phi}^{\times} \\
(\operatorname{expt})\end{array}$ & $\begin{array}{c}\delta^{\mathrm{a}} \\
\left(\mathrm{cal} / \mathrm{cm}^{3}\right)^{1 / 2}\end{array}$ & $\begin{array}{c}Y_{\phi}^{x} \\
\text { (calc) }\end{array}$ & $\frac{\gamma_{d}^{s}(\operatorname{expl})-\gamma_{b}^{x}(\text { calc })}{\gamma_{d}^{x}(\exp t)} \times 100$ \\
\hline$n$-Pentane & 100.6 & 2.62 & 3.59 & 7.17 & 4.04 & -12.5 \\
\hline$n$-Hexane & 312.5 & 2.81 & 3.39 & 7.33 & 3.61 & -6.5 \\
\hline n-Heptane & 943.0 & 3.06 & 3.29 & 7.47 & 3.21 & 2.4 \\
\hline$n$-Octane & 2793 & 3.36 & 3.25 & 7.55 & 2.99 & 8.0 \\
\hline 1-Hexene & 280.5 & 2.54 & 3.19 & 7.38 & 3.40 & 6.6 \\
\hline 1-Heptene & - & - & - & 7.53 & 3.01 & - \\
\hline 1-Oclene & 2518. & 3.00 & 3.01 & 7.61 & 2.79 & 7.3 \\
\hline 1-Nonene & 7589. & 3.24 & 2.95 & 7.73 & 2.45 & 16.9 \\
\hline Benzeıle & 669.9 & 2.07 & 3.67 & 9.20 & 3.94 & -7.4 \\
\hline Toluene & 2120. & 2.18 & 3.23 & 8.91 & 3.32 & -2.8 \\
\hline Elhylbenzene & 5542. & 2.49 & 3.20 & 8.79 & 3.07 & 4.1 \\
\hline$o$-Xylene & 8317. & 2.38 & 3.12 & 8.99 & 3.67 & -17.6 \\
\hline$m$-Xylene & 6763. & 2.34 & 3.00 & 8.82 & 3.15 & -5.0 \\
\hline$n$-Propylbenzene & 13854. & 2.76 & 3.12 & 8.64 & 2.71 & 13.1 \\
\hline \multicolumn{7}{|l|}{ Isopropyl- } \\
\hline benzene & 10623. & 2.66 & 3.00 & 8.61 & 2.64 & 12.0 \\
\hline
\end{tabular}

${ }^{a} 1$ calorie $=4.184$ Joules

physical properties using the Flory-Huggins and the Hildebrand-Scatchard equations.

The quantity $\gamma_{\phi}^{\circ}$ in eq $l$ is defined as the activity coefficient of a solute measured in octanol saturated with water. However, Purnell [15] has shown that $\gamma_{\phi}^{\circ}$ for a solute in a binary mixture may be expressed as

$$
\frac{1}{\gamma_{\phi}^{\circ}}=\frac{\phi_{w}}{\gamma_{\gamma}^{\omega \prime}}+\frac{\phi_{0}}{\gamma_{\phi}^{\infty}}
$$

where $\gamma_{\phi}^{\infty}$ and $\gamma_{\phi}^{w \prime}$ are the solute activity coefficients at infinite dilution in pure octanol and in pure water, respectively, and $\phi_{o}$ and $\phi_{w}$ are their volume fractions. It has beeu reported [16] that at equilibrium the volume fraction of water in octanol is 0.0414 . The value of $\gamma_{\phi}^{\omega}$ for the solutes used in this study vary between 380 and 63,000 while those of $\gamma_{\phi}^{\infty}$ vary between 3.00 and 3.60. Thus the errors involved in assuming $\gamma_{\phi}^{o}=\gamma_{\phi}^{\infty}$ and $\gamma_{\phi}^{w^{\prime}}=\gamma_{\phi}^{w}$ are minimal.

The solute activity coefficients in water, $\gamma_{\phi}^{w}$, listed in column 3 of table 2, were calculated using the experimental log $K_{\mathrm{o} / w}$ and calculated $\log \gamma_{\phi}^{\infty}$ from the Flory-Huggins and Hildebrand-Scatchard equation. Considering that the average standard deviation in the experimental $\log K_{o / w}$ is 0.04 and $\log \gamma_{\phi}^{w}$ is 0.03 , the agreement between the experimental log $\gamma_{\phi}^{w}$ (listed in the last column) and the calculated $\log \gamma_{\phi}^{w}$ is very encouraging.

In summary this study suggests that the solute activity eoefficient $\gamma_{\phi}^{\infty}$, may be calculated accurately using the FloryHuggins and Hildebrand-Seatchard equations, and the solubility of organic eompounds in water may be predicted successfully from the knowledge of their octanol/water partition
TABLE 2. Activity Coefficients and Octanol/Water Partition Coeficients at $25.0^{\circ} \mathrm{C}$.

\begin{tabular}{l|c|c|c|c}
\hline \hline Solute & $\begin{array}{c}\log \gamma_{\phi}^{\circ} \\
\text { calculated }\end{array}$ & $\begin{array}{c}\log K_{\text {oww }}(17) \\
\text { Expcrimental }\end{array}$ & $\begin{array}{c}\log \gamma_{\phi}^{*} \\
\text { calculatcd }\end{array}$ & $\begin{array}{c}\text { Experimental } \\
(17)\end{array}$ \\
\hline$n$-Pentane & 0.61 & 3.62 & 4.23 & 4.19 \\
$n$-Hexane & 0.56 & 4.11 & 4.67 & 4.73 \\
$n$-Heptane & 0.51 & 4.66 & 5.17 & 5.27 \\
$n$-Oclane & 0.48 & 5.18 & 5.66 & 5.80 \\
l-Hexene & 0.53 & 3.39 & 3.90 & 3.99 \\
l-Heptene & 0.48 & 3.99 & 4.47 & 4.58 \\
l-Oetene & 0.45 & 4.57 & 5.02 & 5.24 \\
l-Nonene & 0.39 & 5.15 & 5.54 & 5.82 \\
Benzene & 0.60 & $2.13^{(2)}$ & 2.73 & $2.59^{(2)}$ \\
Toluene & 0.52 & 2.65 & 3.17 & 3.17 \\
Ethyl- & & & & \\
$\quad$ benzene & 0.49 & 3.13 & 3.62 & 3.69 \\
$\begin{array}{l}o-X y l e n e \\
m-X y l e n e\end{array}$ & 0.56 & 3.13 & 3.69 & 3.60 \\
$n$-Propyl- & 0.50 & 3.20 & 3.70 & 3.73 \\
$\quad$ benzene & 0.43 & 3.69 & 4.12 & 4.22 \\
Isopropyl- & & & & \\
benzene & 0.42 & 3.90 & 4.32 & 4.09 \\
\hline
\end{tabular}

coefficients and the solute activity coefficient calculated from the FH-HS equation.

We wish to thank Professor üaniel E. Martire, Georgetown University, Washington, D.C., and Dr. Frederick P. Schwarz of this division for helpful diseussions of the subject material. We also express our appreciation to the Environmental Protection Agency for financial support. 


\section{References}

[1] Mackuy, D.; Bohru, A.; Shiu, W. Y.; Yalkowsky, S. H. Relationships between aqueous solubility and octanol-water partition coefficients. Chemosphere. 2: 701-711; 1980 Deeember.

[2] Hanscl, C.; Quinlan, J. E.; Lawrence, G. L. The linear free-energy relationship bctween parlition cocfficients and the aqueous solubility of organic liqnids. J. Ory. Chem. 33(1): 347-350; 1968 January.

[3] Pransnilz, J. M.; Anderson, T. F.; Grens, E. A.; Eckert, C. A.; Hsiel,, R.; O'Connell, J. P. The Liquid Phase, Chapler $t$ in Computer calculations for multicomponent vapor-liquid and liquid-liquid equilibria. Enylewood Clills, N.J.: Prentice-Hall, Inc.; 1980. 39-81.

[4] Ashworth. A. J.; Everet,, D. H. The solubility of low-moleeular weight lyydrocarbons in non-volatile liqnids. Faraday Soc. Trans. 56(11): 1609-1618; 1960 November.

[5] Meen, D. L.; Morris, F.; Purnell, J. H.: Srivastava, A. P. Gas-liquid ehromalography measured activity eoefficients in non-electrolyle solutions. J. Chem. Soc., Faraday Trans. I. 69(12): 2080-2086; 1973 Deeeniber.

[6] Hildebrand, J. H.; Seott, R. L. Regular solutions. Englewood Clifls, N.J.: Prentice-Hall; 1962. 180 p.

[7] Conder, J. R.; Yonng, C. L. Solution thermodynamics, ehapter 5 in Physico-chemical measureatents by gas-liquid chromatography. New York: John Wiley \& Sons; 1979. 151-221.

[8] Tewari, Y. B.; Martire, D. E.; Sheridan, J. P. Gas-liquid partition ehromatographic determination and theoretieal interpretatiou of activity coefficients for hydrocarbon solute in alkane solvcnts. J. Phys. Chem. 74(11): 2345-2356; 1970 November.
[9] Littlewood, A. B.; Phillips, C. S. G.; Price, D. T. The chromalography of gases and vapours. Part V. Partition analysis with columns of Silicone 702 and of Trilolyl Plosphate. J. Chem. Soc.: 1480-1489; 1955 Part II.

[10] McGlashan, M. L.; Potter, D. J. B. An apparatus for the measurement of the seeond virial coefficients of vapours; the second virial coefficients of some $n$-alkanes and of some mixtnres of $n$-alkanes. Proc. Roy. Soc. A. 267(1331): 478-500; 1962 June.

[11] Dreisbaeh, R. R. Physical properties of ehemieal eompounds. A. C. S. Adv. in Chem Ser. 15; 1955. 536 p.

[12] Dreisluach, R. R. Physieal properties of chemical compounds. A. C. S. adv. in Chem. Ser. 22; 1959. 491 p.

[13] Dreisbach, R. R. Physical properties of chemical compounds. A. C. S. Adv. in Chem. Ser. 29; 1961. 489 p.

[14] Timmermans, J. Physico-chemical constants of pure organic compounds. New York: Elsevier Publishing Co.; 1950. 693 p.

[15] Purnell, J. H.; Vargas de Andrade, J. M. Solution and complexing studies. II. Comparison and correlation of nuclear magnctic resonance and gas-liquid ehromalographie dala. J. Am. Chem. Soc. 91(13): 3590-3593; 1974 June 25.

[16] Leo, A.; Hansch, C. Linear Free-Energy Relalionships between partitioning Solvent Systems. J. Org. Chem., 36(11): 1539-154/; 1971 June 4.

[17] Tewari, Y. B.; Miller, M. M.; Wasik, S. P. and Martire, D. E. Aqueous solubility and octanol/waler partition eoefficients of organic compounds at $25.0^{\circ} \mathrm{C}$. J. Chem. and Eng. Data, (in press). 